\title{
Represión, violencia estatal e historia en el siglo XX en el Cono Sur
}

\author{
(4) Ernesto Bohoslavsky \\ Programa de Historia Contemporánea de la Universidad Nacional de General Sarmiento / \\ CONICET, Argentina. \\ ebohosla@campus.ungs.edu.ar

\section{Marina Franco} \\ Instituto de Altos Estudios Sociales de la Universidad Nacional de San Martín / CONICET, \\ Argentina. \\ mfranco@unsam.edu.ar
}

\section{Presentación}

Tras la explosión de protestas sociales en el último trimestre del 2019 en Chile, no menos de 200 personas tuvieron pérdida o total o parcial de su visión a causa de los disparos realizados ex profeso por fuerzas de seguridad contra los ojos de los manifestantes. Los episodios que siguieron a la renuncia forzada del presidente Evo Morales en 2019 incluyeron violentos ejercicios de represión que dieron por resultado a decenas de civiles asesinados por las fuerzas de seguridad. A ese panorama podríamos sumar el incremento de la persecución y acoso de los cuerpos policiales brasileños sobre movimientos sociales y militantes de organizaciones políticas, de favelados y de diversidades sexuales en ese país desde la asunción de Michel Temer en 2016,y sobre todo tras la asunción de Jair Bolsonaro como presidente. La aceptación del "gatillo fácil" policial en algunos sectores en la Argentina vino a confirmar que el incremento de la violencia estatal contra diversos colectivos (políticos, sociales, étnicos, etc.) parece una dolencia de escala sudamericana más que nacional. Ese giro autoritario de América del sur parece alcanzar niveles desconocidos desde el final de las dictaduras. Como historiadores e historiadoras, nuestra pregunta es si esta violencia estatal represiva -acompañada y blindada con discursos y representaciones racistas, xenofóbicos y elitistas de autoridades y de personas de a pie-, ¿volvieron luego de cierto impasse democrático o si, por el contrario, nunca se fueron?

Este cuadro general de época dio impulso a la organización de una mesa en el III Coloquio Internacional sobre violencia política en el siglo XX/IV Jornadas de Trabajo 
de la Red de estudios sobre represión y violencia política, que se llevó a cabo en la Universidad Nacional de Rosario en abril de 2019 (cuando por entonces aún no se había desencadenado la crisis chilena ni la boliviana). En dicha ocasión convocamos a distintos historiadores e historiadores del Cono Sur (Brasil, Chile, Uruguay, Argentina) para que pensaran y problematizaran, de manera ambiciosa y renovadora, el problema de la violencia estatal a lo largo del siglo XX. Esos textos son los que componen el presente dossier, que tiene por propósito central discutir con los marcos historiográficos nacionales y regionales sobre dos grandes problemas. El primero de ellos es identificar los niveles de continuidad y de ruptura en el uso de dispositivos de represión estatal a lo largo del siglo, en particular entre el tiempo anterior y el posterior a la constitución de los últimos regímenes dictatoriales (Brasil en 1964, Chile y Uruguay en 1973 y Argentina en 1976). A través de la mirada de largo plazo, los artículos incluidos en este dossier se interesan especialmente por inscribir las llamadas "dictaduras de la seguridad nacional" -sin duda los fenómenos represivos más sobresalientes y conocidos- en el largo plazo histórico y se preguntan por las formas en que esos regímenes innovaron, continuaron o ampliaron prácticas y lógicas represivas previas, cuyo régimen de historicidad no parece reducirse al de la historia política ni exclusivamente nacional. El segundo problema aquí abordado es el del peso de la represión en la construcción y mantenimiento de la dominación política nacional en el siglo XX: ¿cuánto de consenso y cuánto de coacción se conjugaron para asegurar el orden político, el acatamiento de los actores subalternos y el encarrilamiento de las disidencias potenciales o reales a lo largo de la centuria y en diferentes configuraciones político-sociales? Entendíamos que estas dos inquietudes guardaban interés tanto historiográfico como político, por cuanto atañían al conocimiento sobre el pasado, pero también a las posibilidades y las formas de la convivencia en sociedad en el presente.

Un propósito adicional que anima este dossier es discutir las características de los procesos represivos en estos cuatro países para, por un lado, superar las fragmentaciones internas de cada sub-campo historiográfico nacional (que habitualmente está recortado por tramos temporales relativamente separados entre sí); y, por otro lado, poner en relación y abrir perspectivas comparadas y conectadas entre los procesos de largo plazo de estos países. Para ello, las intervenciones proponen algunas líneas interpretativas generales que permiten discutir algunas de las visiones historiográficas más consolidadas sobre los rasgos generales del siglo XX en cada país y, a la vez, se atreven a sugerir agendas de trabajo renovadas.

\section{Violencia estatal: definiciones y comparaciones}

La primera y crucial pregunta para abordar este tema es por la definición y límites conceptuales del problema abordado: ¿violencia estatal o represión?, ¿disciplinamiento social o persecución política?, ¿acción represiva o preventiva?, ¿represión estatal y paraestatal? Los contornos del problema son tan amplios y difusos que la delimitación conceptual es central a la hora de definir posibles alcances de la 
investigación empírica. A su vez, esta delimitación conceptual está sistemáticamente amenazada por la aridez para establecer fronteras claras entre fenómenos distintos pero conectados. El ejemplo más claro de ello es la dificultad para distinguir lo que suele definirse como represión política o represión social: ¿si la represión se limita a la persecución de enemigos políticos puede considerarse parte de ella la represión a los sectores obreros o populares cuando éstos, por ejemplo, realizan huelgas?; si la respuesta fuera negativa, ¿podemos entender la represión en el largo plazo y de manera históricamente situada prescindiendo de los momentos en los cuales los sectores obreros o populares no organizados fueron blanco sistemático de ella? ¿qué es político y qué no lo es en una huelga? Vinculado a lo anterior pero a la luz de otro actor clave: ¿qué alcance conceptual del objeto nos permitiría incluir la represión sobre los pueblos indígenas?, ¿cómo separamos el racismo y la violencia estructural sobre ellos de los actos de represión explícita más ocasionales? ¿Es acaso tan clara la distinción entre lo político y lo social? ¿Es acaso una distinción analítica o la hacen los propios contemporáneos? A su vez, si incluimos la represión "social”, ¿cuáles son sus límites? ¿El uso del "gatillo fácil” o la violencia sistemática en los barrios pobres no sería una de sus formas? ¿Cómo establecer necesarias diferenciaciones conceptuales y operativas entre unas formas y otras?

Otra diferenciación necesaria y llena de tensiones a la hora de construir un concepto coherente y operativo es entre el uso de las herramientas preventivas y la coerción física directa: ¿podemos separar las instituciones de inteligencia y su actividad regular de control social y político de las acciones coercitivas abiertas? ¿Qué lugar ocupan la legislación y los dispositivos del poder judicial en la represión?

Una tercera y aún más compleja dificultad reside en plantear el problema de cómo incluir -o hasta dónde es pertinente hacerlo- a las instituciones de disciplinamiento social "clásicas" como son el sistema carcelario y la institución policial. ¿Es acaso legítimo considerarlos cuando son parte del dispositivo de persecución política pero no cuando involucran a delincuentes comunes o a otras formas desviación de la ley? ¿Esa distinción es válida o reconocida para los propios actores de esos sistemas? Por último, si bien parece necesario separar la represión política de la violencia estructural del Estado en la producción y reproducción sistemática de desigualdades, ¿cómo entender la última sin considerar la primera?

Sobre esta serie de dificultades los textos del dossier ensayan respuestas y recortes analíticos distintos que sistemáticamente ponen a prueba estas distinciones, aunque con enormes complicaciones que los propios autores advierten. Los textos de este dossier y esta apretada discusión conceptual nos ponen ante la evidencia, al menos en el estado actual de los desarrollos sobre el tema, que la investigación empírica supone una serie de decisiones operativas que sistemáticamente muestran potencialidades, pero también límites. Sin embargo, sin esos límites y sin esas decisiones -que seguramente pueden variar según los países y momentos históricos- el objeto historiográfico se revela imposible.

El último punto sobre el que queremos llamar la atención, y que -como dijimos más arriba- orientó la construcción de este dossier, es la posibilidad de pensar 
de manera comparada y/o conectada los casos nacionales aquí considerados (sin excluir la posibilidad de que otros casos nacionales puedan insertarse en la misma serie). Poner a prueba esta posibilidad supone avanzar en la construcción de una historia regional más articulada y sensible a sus relaciones y parecidos de lo que nos deja ver el énfasis en las singularidades nacionales, tan propio de la historiografía contemporánea. En ese sentido, la lectura conjunta de los trabajos del dossier sugiere notables similitudes con ciertos procesos regionales y globales; entre ellos es particularmente notoria la persecución a las múltiples amenazas de izquierda y, en particular, del comunismo y el anarquismo en las primeras décadas del siglo, la construcción de enemigos reales y fantasmagóricos en torno a esas identidades en las décadas posteriores; los efectos de la guerra fría y las lógicas de la seguridad nacional en la segunda parte de la centuria. Pero también son comparables los ciclos locales de ampliación de las demandas sociales de cambio y la radicalización política desde mediados de siglo, el uso recurrente de dispositivos represivos en gobiernos constitucionales a través de la legislación de excepción, el desplazamiento de las instituciones policiales a las Fuerzas Armadas como agencias encargadas de la tarea represiva. En todos los trabajos, y especialmente en el caso chileno y uruguayo, es notable la insistencia en mostrar una utilización frecuente -cambiante, discontinua y diferenciada- de las violencias represivas por parte del Estado. Este rasgo no es sólo el resultado del enfoque propuesto para el dossier, sino el reconocimiento de un vacío historiográfico y de ciertas desconexiones en el abordaje de distintos períodos históricos a la hora de pensar un problema de largo plazo. Por tanto, las conexiones y parecidos se nos presentan tanto en el plano histórico como historiográfico y dejan a la vista un auténtico campo de problemas a abordar en múltiples escalas de análisis y dimensiones. Todo ello en un momento regional en el que la discusión sobre los usos políticos de la represión estatal como indicamos al inicio de este texto, vuelven a adquirir centralidad histórica y política.

\section{El dossier: contenidos, sentidos y agradecimientos}

Dada la naturaleza ambiciosa de esta propuesta, se sugirió a los autores producir textos más reflexivos y propositivos que informativos, más historiográficos que históricos. De allí que los cuatro textos que componen este dossier tienen un tono más ensayístico que de investigación histórica empíricamente informada; supusimos que un enfoque de este tipo sería más pertinente y adecuado para dar cuenta de procesos muy extensos en pocas páginas y, a la vez, polemizar y reunir cuestiones historiográficas que habitualmente se presentan disociadas. Los artículos abarcan temas inevitablemente vastos, cabalgan por períodos muy largos y por problemas de envergaduras oceánicas: confiamos en que los lectores acompañen -o al menos toleren- la naturaleza de esta propuesta y también sus inevitables límites. En definitiva se trata de abrir un campo de problemas y preguntas.

El artículo de Rodrigo Patto Sá Motta ofrece un balance historiográfico en el siglo que va desde la proclamación de la república brasileña en 1889 hasta la aprobación de la nueva constitución pos-dictatorial, en 1988. El historiador mineiro 
propone que el Estado brasileño utilizó de manera sistemática la represión sobre las demandas de democratización del régimen político y de distribución de las riquezas: la recurrente defensa armada del statu quo ha constituido la limitación más severa a la posibilidad de que se constituya en Brasil una sociedad democrática y que valore positivamente a la igualdad.

En varios sentidos, la historia uruguaya ofrece contrapuntos respecto de esta situación por la vitalidad democrática y la -comparativamente- achatada pirámide social. Sin embargo, como muestran en su artículo Magdalena Broquetas y Nicolás Duffau, esa noción de la excepcionalidad histórica uruguaya interrumpida por la dictadura en 1973 impide percibir con precisión el hecho de que hubo prácticas represivas e impulsos autoritarios antes de esa fecha. Una mirada de buena parte del siglo XX permite identificar a los dispositivos usados en la represión de las disidencias políticas de manera casi ininterrumpida en una sociedad que, paradójicamente, siguió caracterizándose por la amplia -mas no universal- colaboración entre partidos y lemas y el débil protagonismo de la corporación castrense.

Probablemente, la imagen más difundida de Chile en el último medio siglo sea la Casa de la Moneda humeante, tras el bombardeo del 11 de septiembre de 1973. Verónica Valdivia postula que lo extremo de ese episodio no debe invisibilizar el hecho de que en el medio siglo anterior al golpe de Estado el país careció de consensos sociales básicos, lo cual se expresó en que los gobiernos echaron mano a recurrentes ejercicios de represión contra actores sociales (el movimiento obrero) y políticos (los partidos de izquierda). Hasta finales de los años sesenta la tarea de desactivar la supuesta "amenaza" popular estuvo a cargo de las policías, la justicia, el aparato de inteligencia, que posteriormente le cedieron el paso y la dirección del proceso de control del orden interno a las Fuerzas Armadas.

Por último, nosotros ofrecemos un texto de naturaleza más bien historiográfico, dedicado a los problemas conceptuales y metodológicos del estudio de las formas de represión estatal en Argentina en el siglo XX. Por un lado, insistimos en la necesidad de profundizar el uso de escalas regionales y transnacionales para comprender mejor ciertas prácticas represivas, tradicionalmente clasificadas como "nacionales". Por el otro lado, proponemos reducir la distancia historiográfica presente entre los que estudian la primera mitad del siglo XX y quienes se dedican a la llamada "historia reciente", de manera tal de mensurar mejor los hilos de continuidad y de larga duración de la violencia estatal en la centuria.

Finalmente, quisiéramos poner de manifiesto dos agradecimientos. El primero es hacia los integrantes del comité editorial de este Boletín, quienes se mostraron dispuestos e interesados en que el dossier tuviera espacio en las páginas de la revista. En particular, Juan Luis Martiren trabajó generosamente en la edición de este dossier. El segundo es hacia quienes evaluaron los artículos y contribuyeron de manera anónima, generosa y decisiva para mejorar la calidad de los argumentos, estimular diálogos historiográficos y precisar mejor los sentidos de las intervenciones. A todos ellos agradecemos sus aportes y eximimos de toda responsabilidad en los contenidos. 